\title{
Temporal changes in psychobehavioural responses during the early phase of the COVID-19 pandemic in Malaysia
}

\author{
Li Ping Wong ${ }^{1}$ (i) $\cdot$ Haridah Alias ${ }^{1}$
}

Received: 16 April 2020 / Accepted: 21 July 2020 / Published online: 5 August 2020

(C) Springer Science+Business Media, LLC, part of Springer Nature 2020

\begin{abstract}
Monitoring public psychological and behavioural responses during the early phase of the coronavirus disease 2019 (COVID-19) outbreak is important for the management and control of infection. This study aims to investigate the temporal trend in (1) avoidance and protective behaviors, (2) fear, (3) socio-economic impact, and (4) anxiety levels during the early phase of the COVID-19 pandemic. As a high level of anxiety may have a detrimental impact during an infectious disease outbreak, factors associated with anxiety were also explored. The survey was carried out for 10 weeks and the responses were divided into three periods of around 3 weeks: 25 January-21 February, 22 February-17 March and 18 March-3 April (the period the Malaysian Government issued Movement Control Order). Findings revealed that most of the pyschobehavioural variables showed small increases during first (25 January-21 February) and second (22 February-17 March) periods, and high psychobehavioral responses were reported during the third period. A total of $72.1 \%(95 \% \mathrm{CI}=69.2-75.0)$ reported moderate to severe anxiety as measured by the State-Trait Anxiety Inventory. Factor influencing moderate to severe anxiety is a high perception of severity $(\mathrm{OR}=2.09 ; 95 \% \mathrm{CI}=1.48-2.94)$, high perceived susceptibility $(\mathrm{OR}=1.71 ; 95 \% \mathrm{CI}=1.17-2.50)$, high impact score $(\mathrm{OR}=1.63 ; 95 \% \mathrm{CI}=1.17-2.26)$ and high
\end{abstract}

Electronic supplementary material The online version of this article (https://doi.org/10.1007/s10865-020-00172-z) contains supplementary material, which is available to authorized users.

Li Ping Wong

wonglp@ummc.edu.my

1 Centre for Epidemiology and Evidence-Based Practice, Department of Social and Preventive Medicine, Faculty of Medicine, University of Malaya, 50603 Kuala Lumpur, Malaysia fear score $(\mathrm{OR}=1.47 ; 95 \% \mathrm{CI}=1.01-2.14)$. In conclusion, the psychological and behavioural responses were found to increase with the progression of the outbreak. High anxiety levels found in this study warrant provision of mental health intervention during the early phase of COVID-19 outbreak.

Keywords COVID-19 - SARS-CoV-2 ·

Psychobehavioural $\cdot$ Malaysia $\cdot$ Temporal changes

\section{Introduction}

An outbreak of coronavirus disease 2019 (COVID-19), caused by severe acute respiratory syndrome coronavirus 2 (SARS-CoV-2), was initially detected in Wuhan, China in December 2019. In less than one month the outbreak has since resulted in an epidemic throughout China (Hui et al., 2020; Lu et al., 2020). The new coronavirus rapidly spread across Asian countries and subsequently all around the world within a month of its onset. Malaysia announced the first three cases of SARS-CoV-2 infection on 25 January 2020. At a later date, with increasing cases, various measures were undertaken by the Malaysian government to contain the spread of COVID-19, including extending travel bans for nationals from Iran, Italy and South Korea. On 17 March 2020 the number of confirmed cases in Malaysia had reached 673; this is also the date when the first two fatalities was reported. Subsequently, the country implemented a nationwide movement control order (MCO) to curb the outbreak on 18 March 2020.

Lessons from previous outbreaks, such as SARS, swine flu (H1N1) and Ebola, have gained international recognition for the importance of understanding and monitoring the lay public's psychobehavioural responses during infectious disease outbreaks. Monitoring of psychobehavioural response, 
particularly during the early phase of an outbreak, plays an important role in identifying behavioural gaps and provides important insights for immediate intervention, helping to bring the outbreak under control (Opare et al., 2000; Leung et al., 2005; Leppin \& Aro, 2009). Empirical studies have provided some conceptual-theoretical frameworks regarding psychobehavioural responses during infectious disease outbreaks. For instance, during the SARS outbreaks, a positive association between anxiety level and personal protective behaviour was found (Seto et al., 2003; Leung et al., 2005). During infectious disease outbreaks, tension may surge in the entire community and result in a significant disruption of general well-being, health and economy (Wishnick, 2010; Qiu et al., 2018; Smith et al., 2019). It is important to note that the public often judges personal risk based on their impressions of disease prevalence and death rates, therefore assessment of risk perception is important and changes in risk perception throughout the epidemic warrant appropriate understanding (Herrera \& Meyers, 2019). Most recently, with the current COVID-19 outbreak, the psychological impact of the outbreak intensified when the community was placed under controlled movement or quarantine (Brooks et al., 2020).

Notwithstanding the prominent psychobehavioural consequences during a disease outbreak, to what extent epidemiologists and social scientists have understood the psychobehavioural aspect of the current COVID-19 outbreak in Malaysia is unknown. In the previous $2009 \mathrm{H} 1 \mathrm{~N} 1$ pandemic, epidemic-related psychobehavioural responses of the Malaysian public were reported (Wong \& Sam, 2010) and it is timely that a similar study should be carried out during the current COVID-19 outbreak.

Stress and anxiety during an infectious disease outbreak warrant considerable attention. The community response to an epidemic follows a pattern in which anxiety is highest and behavioral responses are more intense at the beginning of an epidemic (Gaygisiz et al., 2012). Understanding the association between psychobehavioural responses and anxiety during the early phase of the epidemic is important to provide information for timely public health intervention (Leung et al., 2003). The health belief model (HBM) is a social psychological health behavior change model developed to explain and predict health-related behaviors (Janz $\&$ Becker, 1984) and is also an important model used in the development and designing education intervention program (Shahnazi et al., 2015). It is hypothesized that an individual's perception of threats, a construct in the HBM model, influences anxiety (Robinson et al., 2013). Education intervention programs based on the HBM constructs were found to be effective in alleviating anxiety ( $\mathrm{Ji}$ et al., 2019; Shahnazi et al., 2015). The association between the threat perception of the HBM construct and anxiety during the COVID-19 outbreak has never been reported, hence warrants rigorous investigation.

Therefore, the first aim of this study was to determine the temporal change in psychobehavioural issues related to the COVID-19 outbreak, namely avoidance and preventive measures against SARS-CoV-2 infection, fear, impact, and anxiety levels. Secondly, factors (the psychobehavioral factors and threat perception) influencing the level of anxiety, were investigated. These findings will provide insights for the formulation of mitigation measures to manage the negative impact in a timely manner.

\section{Method}

An anonymous Internet-based, cross-sectional survey was commenced on 25 January 2020, the day the first case of SARS-CoV-2 was reported in Malaysia. The survey was carried out over a period of 10 weeks up until 3 April 2020 and the responses were divided into three time periods of around 3 weeks: 25 January-21 February, 22 February-17 March and 18 March-3 April (the period of the MCO). This study captured temporal responses from the study participants along with the number of confirmed COVID-19 cases as shown in Fig. 1. The pyschobehavioural responses were compared among the respondents from these three time periods. Inclusion criteria were that the respondents were from the general public of Malaysia and aged 18-70 years. The researchers used social network platforms (Facebook, Instagram and WhatsApp) to disseminate and advertise the survey link. Respondents who completed the survey received a note to encourage them to disseminate the survey link to all their contacts. All respondents were informed that their participation was voluntary and consent was implied through their completion of the questionnaire.

The questionnaire was developed in English and translated into Bahasa Malaysia, the national language of Malaysia. Questions were presented in both English and Bahasa Malaysia. Local experts validated the content of the questionnaire. Pilot testing was performed on 30 participants to evaluate the clarity of the question items. The pilot testing involved asking participants to respond to the items as participants, and to identify unclear or ambiguous elements about the question items. Qualitative inquiry was used to gather up-close information for improvement from the survey pilot participants. A minor revision was made based on the results of the pilot. Subsequently, the revised questionnaire was further pre-tested before field administration. The survey consisted of questions that assessed: demographic background; preventive measures against SARSCoV-2 infection; perceived susceptibility and severity of becoming infected with SARS-CoV-2; fear associated with 
Fig. 1 The number of cumulative confirmed, active, and recovered cases of COVID-19 in Malaysia during the data collection period

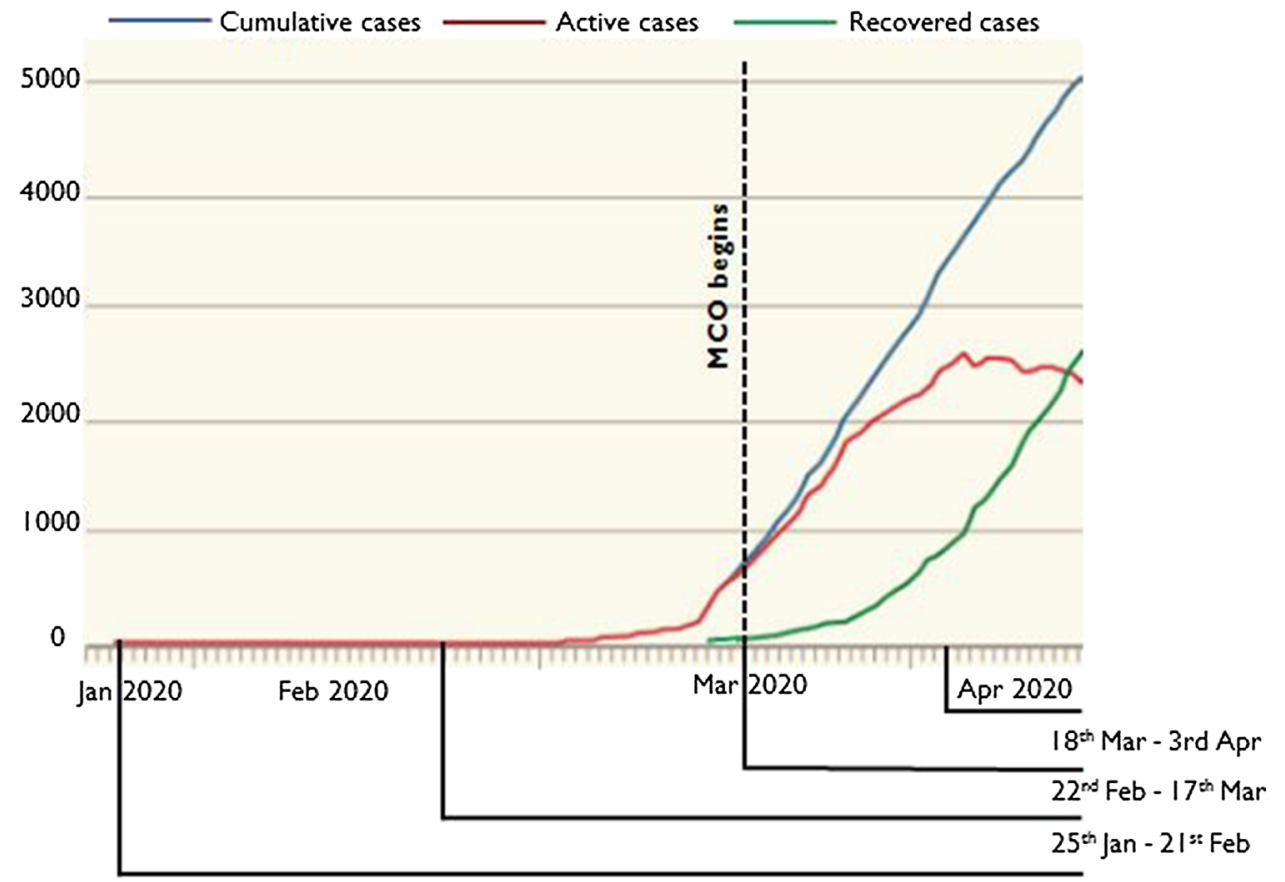

SARS-CoV-2 infection; socio-economic impact; and anxiety level associated with the COVID-19 outbreak.

Questions on demographic characteristics assessed the participants' age, sex, ethnicity, highest educational level, average household income and locality. Questions on prevention practices performed were divided into two sections (11 items): avoidance behaviours (5 items) and protective behaviours (6 items). Questions on perceived susceptibility (1 item) and severity ( 1 item) asked participants to rate their level of likelihood of becoming infected with SARSCoV-2 and their level of worry over SARS-CoV-2 infection, respectively. The combination of perceived susceptibility and severity is referred to as perceived threat, is one of the core constructs in the Health Belief Model (Becker, 1974; Rosenstock, 1974; Champion \& Skinner, 2008).

Perceived fear and socio-economic impact consisted of 4 items and 5 items, respectively. The response options for prevention practices, fear and impact were scored on a fourpoint Likert scale: 1, strongly disagree; 2, disagree; 3, agree; 4 , strongly agree. The response options for perceived susceptibility and severity were also scored on a four-point Likert scale: 1 , not at all; 2, somewhat; 3 , very; 4 , extremely. The scores were summed, with higher scores representing higher prevention measures, perceived severity/susceptibility, fear and impact. Apart from the questions on perception of susceptibility/severity, all the questions were adopted from a previous study (Wong \& Sam, 2010).

Anxiety was measured using the 6-item state version of the State-Trait Anxiety Inventory (STAI-6: Marteau \& Bekker, 1992; Hou et al., 2015). The six items of the STAI in Bahasa Malaysia language was adapted from the validated full 20-item STAI (Hashim et al., 2018). Respondents rated the frequency of experiencing six emotional states, namely being calm, tense, upset, relaxed, content and worried, connected with the current COVID-19 outbreak. A four-point scale was used (1, not at all; 2, somewhat; 3, moderately; 4, very much). The scores on the three positively worded items were reverse coded. The total summed scores were pro-rated (multiplied by 20/6) to obtain scores that were comparable with those from the full 20-item STAI (giving a range of 20-80) (Marteau \& Bekker, 1992). A cut-off score of 44 was used to indicate moderate to severe symptoms (Knight et al., 1983; Leung et al., 2005).

\section{Statistical analysis}

The reliability of the scales used was evaluated by assessing the internal consistency of the items representing the scores. The avoidance and protective behaviour items had a reliability (Cronbach's $\alpha$ ) of 0.921 and 0.707 , respectively. The reliability of the fear and impact items was 0.779 and 0.906 , respectively. The reliability computed for the STAI- 6 items in the assessment of anxiety was 0.781 . To our best knowledge, this study is the first that assess anxiety using 6-item STAI in the Bahasa Malaysia language. The high Cronbach's $\alpha$ value indicates the 6-items STAI in Bahasa Malaysia language has a satisfactory level of internal consistency. Multivariable logistic regression analysis, using a simultaneous forced-entry method, was used to determine the factors influencing moderate to severe anxiety. Odds ratios (OR), 95\% confidence intervals $(95 \% \mathrm{CI})$ and $p$ values were calculated for each independent variable. 
All statistical analyses were performed using the Statistical Package for the Social Sciences, version 20.0 (IBM Corp., Armonk, NY, USA). The level of significance was set at $p<0.05$.

\section{Ethical considerations}

This research was approved by the University of Malaya Research Ethics Committee (UM.TNC2/UMREC - 847).

\section{Results}

A total of 962 completed responses were received. As shown in the first and second columns of Table 1, the mean age \pm standard deviation (SD) of the study participants is $35.5 \pm 11.2$ years. The study has a slightly higher representation of females $(68.6 \%)$, participants with tertiary education level (91.3\%) and from the Central region (67.7\%). With regard to ethnicity, the majority were Malay (58.7\%), followed by Chinese (29.3\%). Figure 2 illustrates the proportions of each pyschobehavioural response and Fig. 3 displays the trend of these responses according to the three time periods.

\section{Avoidance behaviour}

Figure 2.1 shows the proportion of strongly agree/agree responses for avoidance behaviour performed in the three successive time periods. All the avoidance behaviour items showed an increase in the proportion of strongly agree/agree across the three time periods. Highest proportion of all the avoidance behaviours were reported during 18 March-3 April. The highest avoidance behaviour was in relation to 'avoid going abroad'. The overall total avoidance behaviour score was $12.1 \pm 3.5$ out of a possible range of $0-15$. The median was 13 (interquartile range IQR $=10-15$ ). The avoidance behaviour scores were categorized as a score of $13-15$ or $0-12$ based on the median split; thus, 558 (58.0\%; $95 \% \mathrm{CI}=54.8-61.1)$ were categorized as having a score of $13-15$ and $404(42.0 \%$; $95 \% \mathrm{CI}=38.8-45.2)$ with a score of $0-12$. Statistically significant differences were observed in the increase in mean total avoidance behaviour score for respondents during 25 January-21 February (11.2 \pm 3.7$)$, 22 February-17 March (11.8 \pm 3.2$)$ and 18 March-3 April $(13.9 \pm 2.2)$.

\section{Protective behaviour}

Figure 2.2 shows the proportion of strongly agree/agree responses for the three successive time periods. All the avoidance behaviour items showed an increase in the proportion of strongly agree/agree across the three time periods. The highest increment was seen for wearing a mask out in public for 18 March-3 April. The overall total protective behaviour score was $15.0 \pm 2.8$ out of the possible range $0-18$. The total protective behaviour score of the responses in this study ranged from 4 to 18 . The median was $16(\mathrm{IQR}=13-17)$. The protective behaviour scores were categorized as a score of 16-18 or 4-15 based on the median split: thus, $524(54.5 \%$; $95 \% \mathrm{CI}=51.3-57.7)$ were categorized as having a score of $16-18$ and 438 (45.5\%; $95 \% \mathrm{CI}=42.3-48.7)$ with a score of $4-15$. There is a statistically significant difference in the increase in the mean total protective behaviour score for respondents during 25 January-21 February (14.6 \pm 3.0$)$, 22 February-17 March $(14.5 \pm 2.7)$, and 18 March-3 April $(16.0 \pm 2.1)$.

\section{Fear}

Figure 2.3 shows that across the three time periods the highest level of fear was for eating wildlife animals whereas the lowest level was for eating out. The overall total fear score was $10.0 \pm 2.3$ out of a possible range of $0-12$. The median was $11(\mathrm{IQR}=9-12)$. The fear scores were categorized as a score of $11-18$ or $0-10$ based on the median split: thus, 511 $(53.1 \% ; 95 \% \mathrm{CI}=49.9-56.3)$ were categorized as having a score of $11-12$ and $451(46.9 \%$; $95 \% \mathrm{CI}=43.7-50.1)$ with a score of $0-10$. The mean total score for respondents during 18 March-3 April was significantly higher than those of the earlier time periods.

\section{Impact}

Figure 2.4 shows that the highest impact was on the family's daily routine. All the impact items showed an increase in proportion of strongly agree/agree across the three time periods. The overall total impact score was $9.1 \pm 4.7$ out of the possible range of $0-15$. The median was 10 (IQR $=6-13$ ). The impact scores were categorized as a score of 10-15 or $0-9$ based on the median split: thus, $509(52.9 \%$; $95 \% \mathrm{CI}=49.7-56.1)$ were categorized as having a score of $10-15$ and $453(47.1 \%$; $95 \% \mathrm{CI}=43.9-50.3)$ with a score of $0-12$. There is a statistically significant increase in the mean total impact score for respondents during 25 January-21 February 21 (7.6 \pm 4.7$), 22$ February-17 March (9.2 \pm 4.8$)$, and 18 March-3 April (11.9 \pm 2.9 .) Of note, Fig. 3 shows that among all the pyschobehavioural variables the trend line of the total impact scores showed a slightly greater upward slope over time.

\section{Perception of susceptibility and severity}

Respondents during 18 March-3 April reported a higher proportion of extremely/very responses for perception of susceptibility (41.3\%) to becoming infected with SARS-CoV-2 
Table 1 Socio demography, fear, impact, prevention behavior and anxiety level of COVID-19 (N=962)

\begin{tabular}{|c|c|c|c|c|c|}
\hline & $\begin{array}{l}\text { Overall } \\
\mathrm{n}(\%)\end{array}$ & $\begin{array}{l}\text { 25th Jan-21st Feb } \\
(\mathrm{n}=581)\end{array}$ & $\begin{array}{l}\text { 22nd Feb-17th March } \\
(\mathrm{n}=71)\end{array}$ & $\begin{array}{l}\text { 18th March-3rd April } \\
(\mathrm{n}=310)\end{array}$ & $p$ value \\
\hline \multicolumn{6}{|l|}{ Socio demography } \\
\hline Age group $($ mean $\pm \mathrm{SD})$ & $35.5 \pm 11.2$ & $34.7 \pm 10.6$ & $33.1 \pm 14.8$ & $37.5 \pm 11.1$ & $\mathrm{p}<0.001^{\mathrm{a}}$ \\
\hline \multicolumn{6}{|l|}{ Sex } \\
\hline Male & $302(31.4)$ & $156(26.9)$ & $21(29.6)$ & $125(40.3)$ & \multirow[t]{2}{*}{$\mathrm{p}<0.001^{\mathrm{b}}$} \\
\hline Female & $660(68.6)$ & $425(73.1)$ & $50(70.4)$ & $185(59.7)$ & \\
\hline \multicolumn{6}{|l|}{ Ethnicity } \\
\hline Malay & $565(58.7)$ & $280(48.2)$ & $30(42.3)$ & $255(82.3)$ & \multirow[t]{4}{*}{$\mathrm{p}<0.001^{\mathrm{b}}$} \\
\hline Chinese & $282(29.3)$ & $216(37.2)$ & $40(56.3)$ & $26(8.4)$ & \\
\hline Indian & $53(5.5)$ & $38(6.5)$ & $1(1.4)$ & $14(4.5)$ & \\
\hline Bumiputera Sabah/Sarawak/Others & $62(6.4)$ & $47(8.1)$ & $0(0.0)$ & $15(4.8)$ & \\
\hline \multicolumn{6}{|l|}{ Level of education } \\
\hline Secondary school & $84(8.7)$ & $28(4.8)$ & $5(7.0)$ & $51(16.5)$ & \multirow[t]{2}{*}{$\mathrm{p}<0.001^{\mathrm{b}}$} \\
\hline Tertiary & $878(91.3)$ & $553(95.2)$ & $66(93.0)$ & $259(83.5)$ & \\
\hline \multicolumn{6}{|l|}{ Occupation } \\
\hline Professional and managerial & $551(57.3)$ & $368(63.3)$ & $21(29.6)$ & $162(52.3)$ & \multirow[t]{4}{*}{$\mathrm{p}<0.001^{\mathrm{b}}$} \\
\hline General worker & $131(13.6)$ & $52(9.0)$ & $6(8.5)$ & $73(23.5)$ & \\
\hline Student & $173(18.0)$ & $109(18.8)$ & $37(52.1)$ & $27(8.7)$ & \\
\hline Housewife/Retiree/Unemployed/Others & $107(11.1)$ & $52(9.0)$ & $7(9.9)$ & $48(15.5)$ & \\
\hline \multicolumn{6}{|l|}{ Average monthly household income (MYR) } \\
\hline$<2000$ & $97(10.1)$ & $48(8.3)$ & $19(26.8)$ & $30(9.7)$ & \multirow[t]{4}{*}{$\mathrm{p}<0.001^{\mathrm{b}}$} \\
\hline $2001-4000$ & $308(32.0)$ & $172(29.6)$ & $15(21.1)$ & $121(39.0)$ & \\
\hline $4001-8000$ & $311(32.3)$ & $193(33.2)$ & $15(21.1)$ & $103(33.2)$ & \\
\hline$>8000$ & $246(25.6)$ & $168(28.9)$ & $22(31.0)$ & $56(18.1)$ & \\
\hline \multicolumn{6}{|l|}{ Location } \\
\hline Urban & $657(68.3)$ & $436(75.0)$ & $47(66.2)$ & $174(56.1)$ & \multirow[t]{2}{*}{$\mathrm{p}<0.001^{\mathrm{b}}$} \\
\hline Sub urban/Rural & $305(31.7)$ & $145(25.0)$ & $24(33.8)$ & $136(43.9)$ & \\
\hline \multicolumn{6}{|l|}{ Region $^{\dagger}$} \\
\hline Central & $651(67.7)$ & $401(69.0)$ & $42(59.2)$ & $208(67.1)$ & \multirow[t]{5}{*}{$\mathrm{p}<0.001^{\mathrm{b}}$} \\
\hline Southern & $71(7.4)$ & $42(7.2)$ & $5(7.0)$ & $24(7.7)$ & \\
\hline Northern & $89(9.3)$ & $53(9.1)$ & $7(9.9)$ & $29(9.4)$ & \\
\hline East Coast & $74(7.7)$ & $22(3.8)$ & $15(21.1)$ & 37 (11.9) & \\
\hline Borneo Island & $77(8.0)$ & $63(10.8)$ & $2(2.8)$ & $12(3.9)$ & \\
\hline \multicolumn{6}{|l|}{ Prevention behaviour } \\
\hline $\begin{array}{l}\text { Mean total avoidance behavior score } \\
\quad(\text { mean } \pm \text { SD })\end{array}$ & $12.1 \pm 3.5$ & $11.2 \pm 3.7$ & $11.8 \pm 3.2$ & $13.9 \pm 2.2$ & $\mathrm{p}<0.001^{\mathrm{a}}$ \\
\hline $\begin{array}{l}\text { Mean total protective behavior score } \\
\quad(\text { mean } \pm \text { SD })\end{array}$ & $15.0 \pm 2.8$ & $14.6 \pm 3.0$ & $14.5 \pm 2.7$ & $16.0 \pm 2.1$ & $\mathrm{p}<0.001^{\mathrm{a}}$ \\
\hline \multicolumn{6}{|l|}{ Fear of COVID-19 } \\
\hline Mean total fear score $($ mean \pm SD) & $10.0 \pm 2.3$ & $9.6 \pm 2.4$ & $9.3 \pm 2.5$ & $10.9 \pm 1.7$ & $\mathrm{p}<0.001^{\mathrm{a}}$ \\
\hline \multicolumn{6}{|l|}{ Impact from COVID-19 } \\
\hline Mean total impact score $($ mean \pm SD) & $9.1 \pm 4.7$ & $7.6 \pm 4.7$ & $9.2 \pm 4.8$ & $11.9 \pm 2.9$ & $\mathrm{p}<0.001^{\mathrm{a}}$ \\
\hline \multicolumn{6}{|l|}{ Perceived susceptibility } \\
\hline Very/Extremely & $294(30.6)$ & $26.3(95 \%$ CI $22.8-30.1)$ & $18.3(95 \%$ CI $10.1-29.3)$ & 58.7 (95\%CI 53.0-64.2) & $\mathrm{p}<0.001^{\mathrm{b}}$ \\
\hline \multicolumn{6}{|l|}{ Perceived severity } \\
\hline Very/Extremely & $736(76.5)$ & 72.6 (95\%CI 68.8-76.2) & 70.4 (95\%CI 58.4-80.7) & $85.2 \%$ (95\%CI 80.7-88.8) & $\mathrm{p}<0.001^{\mathrm{b}}$ \\
\hline \multicolumn{6}{|l|}{ Anxiety } \\
\hline Total anxiety score & $52.0 \pm 13.0$ & $50.9 \pm 13.2$ & $52.1 \pm 12.7$ & $54.0 \pm 12.5$ & $0.003^{\mathrm{a}}$ \\
\hline Moderate/Severe (score 44-80) & $694(72.1)$ & $69.0(95 \%$ CI $65.1-72.8)$ & 74.6 (95\%CI 62.9-84.2) & 77.4 (95\%CI 72.4-82.0) & $0.026^{\mathrm{b}}$ \\
\hline
\end{tabular}

${ }^{\dagger}$ Central: Selangor, Kuala Lumpur, Putrajaya, Negeri Sembilan, Malacca; Southern: Johor; Northern: Perlis, Kedah, Pulau Pinang, Perak; East Coast: Terengganu, Kelantan, Pahang; Borneo Island: Sabah, Sarawak, Labuan

${ }^{\mathrm{a} O n e-W a y ~ A N O V A}$

${ }^{\mathrm{b}} \mathrm{Chi}$-square test 

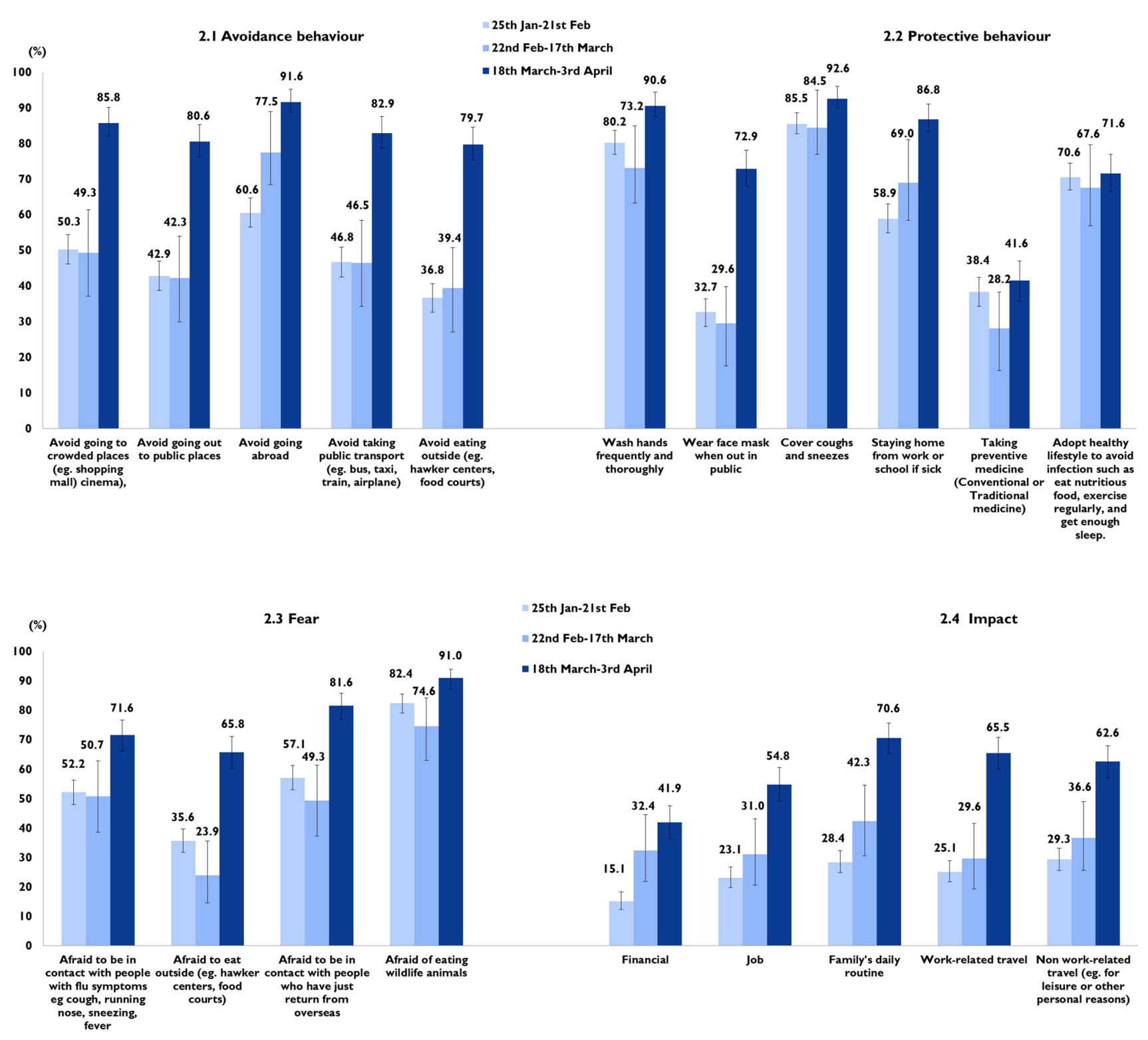

Fig. 2 Proportion of strongly agree/agree for avoidance and protective behaviours, fear, and impact $(\mathrm{N}=962)$

compared to those of 25 January-21 February (26.3\%) and 22 February-17 March (18.3\%). Likewise, respondents during 18 March-3 April reported a higher proportion of extremely/very responses for perception of severity (83.2\%) of SARS-CoV-2 infection compared to those of 25 January-21 February (70.4\%) and 22 February-17 March (72.6\%). On the whole, a higher proportion of participants expressed higher susceptibility than severity of SARS$\mathrm{CoV}-2$ infection across the three time periods.

\section{Anxiety levels}

Using a cut-off score of 44 for the STAI score, a total of $72.1 \%(n=694,95 \% \mathrm{CI}=69.2-75.0)$ of the overall respondents reported moderate to severe anxiety. The proportion of respondents with moderate to severe anxiety during 25 January-21 February, 22 February-17 March and 18 March-3 April was $69.0 \%(95 \% \mathrm{CI}=65.1-72.8), 74.6 \%$ $(95 \% \mathrm{CI}=62.9-84.2)$ and $77.4 \%(95 \% \mathrm{CI}=72.4-82.0)$, respectively. All the psychobehavioural variables were found to be significantly associated with anxiety levels in the univariate analyses. However, none of the demographic characteristics were significantly associated with anxiety levels. There was an inverse association between income and level of anxiety, although the association is not significant. Respondents with income below MYR2000 reported the highest proportion having moderate and severe anxiety (75.3\%), followed by MYR2001-4000 (73.4\%), 
Fig. 3 Trend of mean total score of avoidance and protective behaviours, fear, impact, and anxiety $(\mathrm{N}=962)$

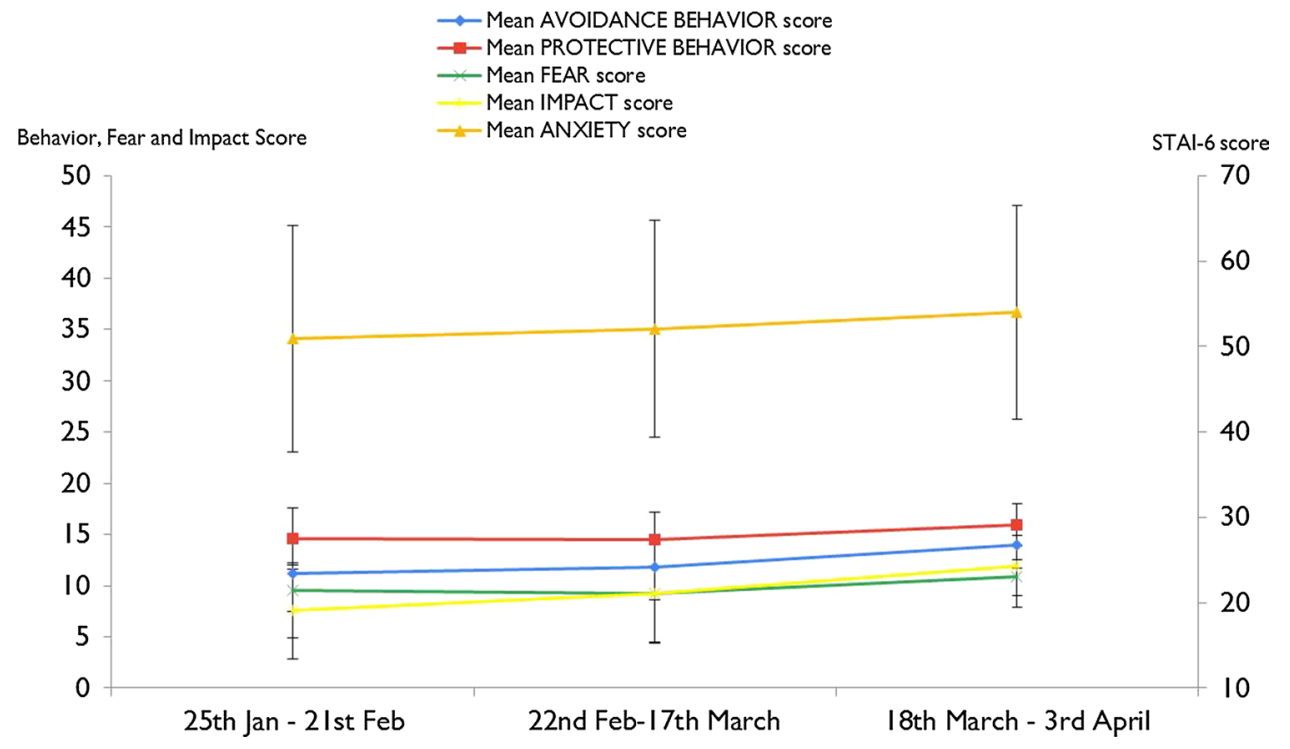

MYR4001-8000 (71.1\%) and above MYR8000 (70.7\%; $p=0.771)$. A total of $73.9 \%$ females reported having moderate to severe anxiety compared to only $68.2 \%$ in males $(p=0.075)$. For ethnicity, a higher proportion of Indians reported moderate to severe anxiety $(77.4 \%)$ compared to only $74.2 \%$ among the Malays and $69.1 \%$ among the Chinese $(p=0.124)$.

Table 2 shows the multivariable logistic regression analysis of factors associated with moderate to severe anxiety. In the multivariate model, the most important factor influencing

Table 2 Multivariable logistic regression analysis of factors associated with moderate to severe anxiety $(\mathrm{N}=962)$

\begin{tabular}{|c|c|c|c|}
\hline & Frequency $(\%)$ & $\begin{array}{l}\text { Univariate } \\
\text { Moderate/Severe anxiety (Score } \\
44-80 \text { ) }\end{array}$ & $\begin{array}{l}\text { Multivariable logistic regression } \\
\text { Score } 44-80 \text { vs } 20-43 \text { OR }(95 \% \mathrm{CI})\end{array}$ \\
\hline \multicolumn{4}{|l|}{ Perceived susceptibility } \\
\hline \multicolumn{4}{|c|}{ Likelihood to be infected by COVID-19 } \\
\hline Not at all/Somewhat & $668(69.4)$ & $446(66.8)$ & Ref \\
\hline Very/Extremely & $294(30.6)$ & $248(84.4)$ & $1.71(1.17-2.50)^{* *}$ \\
\hline \multicolumn{4}{|l|}{ Perceived severity } \\
\hline \multicolumn{4}{|c|}{ Worry about consequences from COVID-19 } \\
\hline Not at all/Somewhat & $226(23.5)$ & $119(52.7)$ & Ref \\
\hline Very/Extremely & $736(76.5)$ & $575(78.1)$ & $2.09(1.48-2.94)^{* * *}$ \\
\hline \multicolumn{4}{|l|}{ Fear } \\
\hline Score $0-10$ & $451(46.9)$ & $283(62.7)$ & Ref \\
\hline Score $11-12$ & $511(53.1)$ & $411(80.4)$ & $1.47(1.01-2.14)^{*}$ \\
\hline \multicolumn{4}{|l|}{ Impact } \\
\hline Score $0-9$ & $453(47.1)$ & $283(62.5)$ & Ref \\
\hline Score $10-15$ & $509(52.9)$ & $411(80.7)$ & $1.63(1.17-2.26)^{* *}$ \\
\hline \multicolumn{4}{|l|}{ Avoidance behavior } \\
\hline Score $0-12$ & $404(42.0)$ & $257(63.6)$ & Ref \\
\hline Score $13-15$ & $558(58.0)$ & $437(78.3)$ & $1.06(0.73-1.53)$ \\
\hline \multicolumn{4}{|l|}{ Protective behaviour } \\
\hline Score 4-15 & $438(45.5)$ & $285(65.1)$ & Ref \\
\hline Score $16-18$ & $524(54.5)$ & $409(78.1)$ & $1.18(0.85-1.65)$ \\
\hline
\end{tabular}

$* \mathrm{p}<0.05 * * \mathrm{p}<0.01, * * * \mathrm{p}<0.001$

Hosmer-Lemeshow test, Chi-square: 3.985, p-value: 0.858; Nagelkerke $R^{2}$ : 0.134 
moderate to severe anxiety is a high perception of severity $(\mathrm{OR}=2.09 ; 95 \% \mathrm{CI}=1.48-2.94)$, followed by high perceived susceptibility $(\mathrm{OR}=1.71 ; 95 \% \mathrm{CI}=1.17-2.50)$, high impact score $(\mathrm{OR}=1.63 ; 95 \% \mathrm{CI}=1.17-2.26)$ and high fear score $(\mathrm{OR}=1.47 ; 95 \% \mathrm{CI}=1.01-2.14)$.

\section{Discussion}

In view of the urgency and importance of identifying current psychobehavioural issues, as well as providing information for those segments of the population that most need psychobehavioural interventions, our findings are summarized over a period of 10 weeks from the start of data collection and include 2 weeks when the country was under the MCO. We hope that the results from this study will provide insights for the health authorities to use when developing risk communication messages during the current escalating COVID19 epidemic in Malaysia, so that appropriate intervention can be carried out to help curb the current escalating outbreak and also ensure the well-being of the public while the outbreak is ongoing.

The MCO order included the closure of schools and higher education institutions, and general prohibition of mass movements and gatherings across the country including religious, sports, social and cultural activities. Although many industries and businesses were not allowed to operate, however, restaurants and cafes were allowed but the regulations only allowed takeaways and deliveries. During the MCO, Malaysians were confined to a $10 \mathrm{~km}$ radius from homes. Violators of the MCO's regulation were subjected to various penalties under the Penal Code. In general, the study respondents from 18 March-3 April, which covers the first 2 weeks of the MCO, have a higher level of avoidance behaviour compared to respondents in the two earlier periods of the study. As such, the MCO has resulted in a surge in avoidance practices among respondents including eating outside, taking public transportation, and going out to public places. Of important note, during the MCO period, Malaysia has put China, Japan, South Korea, Italy, and Iran on a travel ban list. Imposing travel bans have most likely lead to a high proportion of study participants reported avoiding travel abroad. The increase in avoidance behavior along with the progression of the COVID-19 outbreak found in the current study was similar to the study done during the previous H1N1 outbreak in the Malaysia in year 2009 study (Wong \& Sam, 2010).

The study identified some gaps in preventive measures, the most important being the wearing of masks. Less than one-third of participants before the MCO period were found to wear masks when they were out in public. Nearly $27 \%$ reported not wearing masks when out in public during the MCO period, which deserves serious attention. It should be noted that during the study period, using a face mask was encouraged but it is not compulsory. This perhaps led to a lower proportion reported using mask during the two earlier time periods where the number of confirmed COVID-19 cases were relatively low. Subsequently, the proportion of face mask use increased in line with the increase of confirmed cases. Of note, the increase of the SARS-CoV-2 infection in China and subsequently in Malaysia has caused a surge in demand, leading to a shortage of mask supply in the market during the two earlier time periods. This perhaps was one of the reasons people not wearing face masks.

In view of the SARS-CoV-2 infection being extremely contagious, our findings underscore the importance of public health intervention to reach individuals with poor adherence to preventive measures, especially the use of face masks. Earlier, the World Health Organization (WHO) did not recommended wearing masks in community settings as no evidence is available for its usefulness (WHO, 2020a). However, its latest recommendation advises wearing face masks in public areas where social distancing can be difficult (WHO, 2020b), and this should be made known to the public. It is widely known that the shortage of face masks could be the reason why people are not using them, therefore the public should be advised to use another form of facial protection, such as cloth masks, when a face mask is not available. Although they are not as effective as surgical masks, research suggests that they can limit droplet transmission from infected individuals (Davies et al., 2013).

Previous SARS epidemics and the 2015 Middle East Respiratory Syndrome (MERS) outbreak revealed that people's fear, anxiety and infection sensitivity appear to have a positive impact by trigger care-seeking and personal health protection (Leung et al., 2003; Chang et al., 2004; Lee et al., 2016). Importantly, this study has found that the feeling of fear was relatively low among the study respondents, particularly the fear of going to public eateries from the early phase of the COVID-19 outbreak up to and during the MCO period. Community messages encouraging people to stay at home, avoid visiting public places, practise social distancing and pack their food instead of eating outside have been widely circulated since the beginning of the MCO period. The public therefore should be enlightened to avoid public places, as it has been widely recommended that sustainable social distancing and rigorous implementation of social distancing are needed to contain the COVID-19 outbreak (Wilder-Smith et al., 2020).

Results from this study also indicated that a sizeable proportion of study participants were greatly impacted by the COVID-19 outbreak, particularly in their family's daily routine and both non-work and work-related travel. Although official data on the economic impact of COVID-19 in Malaysia are not yet available, nationwide movement control has had a big impact on work-related travel and jobs, as found 
in this study. At the moment, with slightly over 2 weeks of the MCO, the financial impact is approaching 50\%, indicating the potential catastrophic impact of COVID-19 to the economics of Malaysia in the coming future. There is thus an urgent need to mitigate any potential economic fallout of the coronavirus economic crisis. Furthermore, the trend line of the total impact scores showed a slightly greater upward slope over time compared to other psychobehavioural variables, implying increasing social and economic impact as the outbreak progresses. These findings warrant immediate mitigations to strengthen community resilience in order to endure these impacts during the COVID-19 outbreak.

Risk perception, or an individual's perceived susceptibility to a threat, is an important determinant of protective behaviour. Responses to the H1N1 influenza outbreak in 2009 showed that the success of public health intervention programmes is dependent on individual risk perception (Ibuka et al., 2010; Carlsen \& Glenton, 2016). Importantly, the perceived severity of SARS-CoV-2 infection is higher than the perception of susceptibility. Since the beginning of the COVID-19 epidemic in the epicentre, Wuhan, the escalating confirmed cases and deaths from coronavirus in China have received extensive coverage in Malaysia. Of note, this survey commences on the day that the first case of SARS-CoV-2 infection was reported in Malaysia. Despite extensive media coverage and even after the first confirmed case in Malaysia, the perception of susceptibility remains low among participants.

The findings of over two-thirds of the study respondents suffering moderate to severe anxiety indicated that COVID-19 has a strong influence on the mental health of the people of Malaysia. A recent study conducted during the COVID-19 outbreak in China reported that females experience higher psychological impact than males (Wang et al., 2020) and a higher proportion of females reported moderate to severe anxiety than males; nevertheless, these differences were not significant. The current study is unable to provide recommendations on high-risk demographic groups for psychological intervention as there was no significant association between anxiety level and respondents' demographic characteristics. Future research involving a larger sample size is needed to further explore the potential sociodemographic differences in psychological impact associated with COVID-19.

The finding of an increased proportion of respondents with a moderate to severe perception of severity over time is worrisome. Currently, the number of COVID-19 cases is still increasing in Malaysia and the pandemic has yet to reach its peak. This may indicate that a higher proportion of the public may experience anxiety disorders as the epidemic progresses. Multivariable analysis showed that having a high perception of severity and susceptibility is an important determinant of a high anxiety level. The public is more likely to express higher anxiety levels if they perceive they are at risk of becoming infected with SARS-CoV-2: for instance, if someone in their community is infected. This finding supports the hypothesis that risk perception is higher when a health threat is high, uncontrollable or dreaded (Ferrer \& Klein, 2015). Previous studies have reported the benefit of a higher perception of susceptibility and severity in triggering a higher practice of recommended prevention measures during disease outbreak (Lau et al., 2005; Leung et al., 2005; Rubin et al., 2009). There is therefore a need to develop appropriate public educational messages that impart accurate information about the new COVID-19 outbreak yet at the same time do not overestimate the likelihood of infection or underestimate the risk of infection.

In this study the increase in anxiety among those with high socio-economic impact is anticipated. The COVID-19 outbreak has affected both the economic and social wellbeing of the public. On the whole, our findings support the crucial need for the development and implementation of mental health support, treatment and services for the public in Malaysia during the current COVID-19 outbreak (Xiang et al., 2020). It is particularly important for the public to maintain a moderate level of anxiety, as extreme anxiety may impair immune system functioning and increase the risk of infection (Marshall, 2011).

The findings in the current study may provide valuable information for countries in the early phase of the COVID19 outbreak as well as countries currently experiencing an increase in COVID-19 incidence to closely monitor the general public's anxiety and psychobehavioral responses. Prompt diagnosis and delivery of mental health support are important to the affected persons. Assessment of pychobehavioral responses during the ongoing of the COVID-19 outbreak enables timely identification of critical help-seeking issues for proactive intervention.

As with all studies, it is worth noting a few limitations of the present study, particularly concerning the study design and data collection method. Firstly, due to the cross-sectional design, the directionality of the association or the causal relationship between risk perception, fear, impact and anxiety levels could not be established; however, the findings provide a basis for acquiring and testing a causal hypothesis. Due to various resource limitations during the disease crisis and movement restriction in Malaysia, convenient sampling using an online web-based survey via a social media platform may lead to selection bias, as reflected in the large sample of females, people of higher education and the majority being from the Central region. Hence, the lower-educated people and people living in remote areas were under-represented. Despite the lack of general population representativeness, which may affect the generalisability of our findings, the current study provides useful first-hand information on public psychobehavioural responses during 
the early phase of COVID-19 outbreak. It is also noteworthy to mention that the STAI is a measure of people's general level of anxiety. Hence, other sources of anxiety not related COVID-19 outbreak cannot be ruled out. In view of the above limitations, the findings of this study should be interpreted with caution.

\section{Conclusions}

Overall, the public psychological and behavioural responses were found to increase with progression of the COVID-19 outbreak similar to the previous H1N1 outbreak in Malaysia in year the 2009. The majority have a high level of preventive measures and perception of severity of SARS-CoV-2 infection but perception of susceptibility is relatively low. A sizeable proportion of study participants were greatly impacted by the COVID-19 outbreak in their family's daily routine and both non-work and work-related travel. The larger increase in social and economic impact as the outbreak progresses warrants immediate mitigations to strengthen community resilience in order to endure these impacts during the COVID-19 outbreak. A high anxiety level was observed during all three time periods. The factor influencing higher anxiety was a high perception of severity and susceptibility, impact and fear. This timely psychobehavioural assessment during the early phase of the current COVID-19 epidemic among the Malaysian public is valuable for providing insights into strategies for health risk communication and mental health intervention as the COVID-19 pandemic progresses.

Acknowledgements We are grateful for the time that the participants gave to this study.

Authors' contributions All authors contributed to the study conception and design. Material preparation, data collection and analysis were performed by LPW and HA. The first draft of the manuscript was written by LP Wong and all authors commented on previous versions of the manuscript. All authors read and approved the final manuscript.

Funding This study was financially supported by the Ministry of Education Malaysia under Long Term Research Grant Scheme (LRGS MYRUN Phase 1: LRGS MYRUN/F1/01/2018).

\section{Compliance with ethical standards}

Conflict of interest The authors declare that they have no conflict of interest.

Human and animal rights All procedures performed in studies involving human participants were in accordance with the ethical standards of the institutional research committee University of Malaya Research Ethics Committee (UM.TNC2/UMREC - 847).
Informed consent Informed consent was obtained from all patients for being included in the study.

\section{References}

Becker, M. H. (1974). The health belief model and personal health behavior. Health Education Monographs, 2, 324-473.

Brooks, S. K., Webster, R. K., Smith, L. E., Woodland, L., Wessely, S., Greenberg, N., et al. (2020). The psychological impact of quarantine and how to reduce it: Rapid review of the evidence. The Lancet, 395, 912-920. https://doi.org/10.1016/S0140-6736(20)30460 $-8$

Carlsen, B., \& Glenton, C. (2016). The swine flu vaccine, public attitudes, and researcher interpretations: A systematic review of qualitative research. BMC Health Services Research, 16, 203. https:// doi.org/10.1186/s12913-016-1466-7

Champion, V. L., \& Skinner, C. S. (2008). The health belief model. Health Behavior and Health Education: Theory, Research, and Practice, 4, 45-65.

Chang, H. J., Huang, N., Lee, C. H., Hsu, Y. J., Hsieh, C. J., \& Chou, Y. J. (2004). The impact of the SARS epidemic on the utilization of medical services: SARS and the fear of SARS. American Journal of Public Health, 94, 562-564. https://doi.org/10.2105/ ajph.94.4.562

Davies, A., Thompson, K. A., Giri, K., Kafatos, G., Walker, J., \& Bennett, A. (2013). Testing the efficacy of homemade masks: Would they protect in an influenza pandemic? Disaster Medicine and Public Health Preparedness, 7, 413-418. https://doi.org/10.1017/ dmp.2013.43

Ferrer, R. A., \& Klein, W. M. (2015). Risk perceptions and health behavior. Current Opinion in Psychology, 5, 85-89. https://doi. org/10.1016/j.copsyc.2015.03.012

Gaygısız, Ü., Gaygısız, E., Özkan, T., \& Lajunen, T. (2012). Individual differences in behavioral reactions to $\mathrm{H} 1 \mathrm{~N} 1$ during a later stage of the epidemic. Journal of Infection and Public Health, 5, 9-21. https://doi.org/10.1016/j.jiph.2011.09.008

Hashim, E., Hasyila, W. W., Ang, Y., Helmy, A. A., \& Husyairi, H. (2018). Psychometric properties of the Malay Translated Spielberger State-Trait Anxiety Inventory in exploring parental anxiety. Med Health, 13, 106-116. https://doi.org/10.17576 /MH.2018.130.11

Herrera, J. L., \& Meyers, L. A. (2019). Local risk perception enhances epidemic control. PLoS ONE, 14, e0225576.

Hou, W. K., Hall, B. J., Canetti, D., Lau, K. M., Ng, S. M., \& Hobfoll, S. E. (2015). Threat to democracy: Physical and mental health impact of democracy movement in Hong Kong. Journal of Affective Disorders, 186, 74-82. https://doi.org/10.1016/j. jad.2015.07.005

Hui, D. S., Azhar, E. I., Madani, T. A., Ntoumi, F., Kock, R., Dar, O., et al. (2020). The continuing 2019-nCoV epidemic threat of novel coronaviruses to global health-The latest 2019 novel coronavirus outbreak in Wuhan, China. International Journal of Infectious Diseases, 91, 264-266.

Ibuka, Y., Chapman, G. B., Meyers, L. A., Li, M., \& Galvani, A. P. (2010). The dynamics of risk perceptions and precautionary behavior in response to 2009 (H1N1) pandemic influenza. BMC Infectious Diseases, 10, 296. https://doi. org/10.1186/1471-2334-10-296

Janz, N. K., \& Becker, M. H. (1984). The health belief model: A decade later. Health Education Quarterly, 11, 1-47. https://doi. org/10.1177/109019818401100101

Ji, M., Wang, A. H., Ye, J., Shen, Y. H., Chen, C. M., Yu, C., et al. (2019). Effects of the health belief model following acute 
exacerbation of chronic obstructive pulmonary disease in a hospital in China. Journal of Thoracic Disease, 11, 3593. https://doi. org/10.21037/jtd.2019.07.40

Knight, R. G., Waal-Manning, H. J., \& Spears, G. F. (1983). Some norms and reliability data for the State-Trait Anxiety Inventory and the Zung Self-Rating Depression scale. British Journal of Clinical Psychology, 22, 245-249. https://doi. org/10.1111/j.2044-8260.1983.tb00610.x

Lau, J. T., Yang, X., Pang, E., Tsui, H. Y., Wong, E., \& Wing, Y. K. (2005). SARS-related perceptions in Hong Kong. Emerging Infectious Diseases, 11, 417. https://doi.org/10.3201/eid1103.040675

Lee, S. Y., Yang, H. J., Kim, G., Cheong, H. K., \& Choi, B. Y. (2016). Preventive behaviors by the level of perceived infection sensitivity during the Korea outbreak of Middle East Respiratory Syndrome in 2015. Epidemiology and Health, 38, e2016051. https://doi. org/10.4178/epih.e2016051

Leppin, A., \& Aro, A. R. (2009). Risk perceptions related to SARS and avian influenza: Theoretical foundations of current empirical research. International Journal of Behavioral Medicine, 16, 7-29. https://doi.org/10.1007/s12529-008-9002-8

Leung, G. M., Ho, L. M., Chan, S. K., Ho, S. Y., Bacon-Shone, J., Choy, R. Y., et al. (2005). Longitudinal assessment of community psychobehavioral responses during and after the 2003 outbreak of severe acute respiratory syndrome in Hong Kong. Clinical Infectious Diseases, 40, 1713-1720. https://doi.org/10.1086/429923

Leung, G. M., Lam, T. H., Ho, L. M., Ho, S. Y., Chan, B. H. Y., Wong, I. O. L., et al. (2003). The impact of community psychological responses on outbreak control for severe acute respiratory syndrome in Hong Kong. Journal of Epidemiology and Community Health, 57, 857-863. https://doi.org/10.1136/jech.57.11.857

Lu, H., Stratton, C. W., \& Tang, Y. W. (2020). Outbreak of pneumonia of unknown etiology in Wuhan, China: The mystery and the miracle. Journal of Medical Virology. https://doi.org/10.1002/ jmv. 25678

Marshall, G. D. (2011). The adverse effects of psychological stress on immunoregulatory balance: Applications to human inflammatory diseases. Immunology and Allergy Clinics, 31, 133-140. https:// doi.org/10.1016/j.iac.2010.09.013

Marteau, T. M., \& Bekker, H. (1992). The development of a six-item short-form of the state scale of the Spielberger State-Trait Anxiety Inventory (STAI). British Journal of Clinical Psychology, 31, 301-306. https://doi.org/10.1111/j.2044-8260.1992.tb00997.x

Opare, C., Nsiire, A., Awumbilla, B., \& Akanmori, B. D. (2000). Human behavioural factors implicated in outbreaks of human anthrax in the Tamale municipality of northern Ghana. Acta Tropica, 76, 49-52. https://doi.org/10.1016/S0001-706X(00)00089-9

Qiu, W., Chu, C., Mao, A., \& Wu, J. (2018). The impacts on health, society, and economy of SARS and H7N9 outbreaks in China: A case comparison study. Journal of Environmental and Public Health. https://doi.org/10.1155/2018/2710185

Robinson, O. J., Vytal, K., Cornwell, B. R., \& Grillon, C. (2013). The impact of anxiety upon cognition: Perspectives from human threat of shock studies. Frontiers in Human Neuroscience, 7, 203. https ://doi.org/10.3389/fnhum.2013.00203

Rosenstock, I. M. (1974). Historical origins of the health belief model. Health Education Monographs, 2, 328-335. https://doi. org/10.1177/109019817400200403
Rubin, G. J., Amlôt, R., Page, L., \& Wessely, S. (2009). Public perceptions, anxiety, and behaviour change in relation to the swine flu outbreak: Cross sectional telephone survey. BMJ, 339, b2651. https://doi.org/10.1136/bmj.b2651

Seto, W. H., Tsang, D., Yung, R. W. H., Ching, T. Y., Ng, T. K., Ho, M., \& Advisors of Expert SARS group of Hospital Authority. (2003). Effectiveness of precautions against droplets and contact in prevention of nosocomial transmission of severe acute respiratory syndrome (SARS). The Lancet, 361, 1519-1520. https://doi. org/10.1016/s0140-6736(03)13168-6

Shahnazi, H., Sabooteh, S., Sharifirad, G., Mirkarimi, K., \& Hassanzadeh, A. (2015). The impact of education intervention on the Health Belief Model constructs regarding anxiety of nulliparous pregnant women. Journal of Education and Health Promotion, 4, 27. https://doi.org/10.4103/2277-9531.154120

Smith, K. M., Machalaba, C. C., Seifman, R., Feferholtz, Y., \& Karesh, W. B. (2019). Infectious disease and economics: The case for considering multi-sectoral impacts. One Health, 7, 100080. https:// doi.org/10.1016/j.onehlt.2018.100080

Wang, C., Pan, R., Wan, X., Tan, Y., Xu, L., Ho, C. S., et al. (2020). Immediate psychological responses and associated factors during the initial stage of the 2019 coronavirus disease (COVID-19) epidemic among the general population in China. International Journal of Environmental Research and Public Health, 17, 1729. https://doi.org/10.3390/ijerph17051729

WHO. (2020a, January 29). Advice on the use of masks in the community, during home care and in health care settings in the context of the novel coronavirus (2019-nCoV) outbreak: Interim guidance. Retrieved from https://apps.who.int/iris/handle/10665/330987

WHO. (2020b, April 6). Advice on the use of masks in the context of COVID-19. Retrieved from https://www.who.int/publicatio ns-detail/advice-on-the-use-of-masks-in-the-community-durin g-home-care-and-in-healthcare-settings-in-the-context-of-thenovel-coronavirus-(2019-ncov)-outbreak

Wilder-Smith, A., Chiew, C. J., \& Lee, V. J. (2020). Can we contain the COVID-19 outbreak with the same measures as for SARS? The Lancet Infectious Diseases. https://doi.org/10.1016/s1473 $-3099(20) 30129-8$

Wishnick, E. (2010). Dilemmas of securitization and health risk management in the People's Republic of China: The cases of SARS and avian influenza. Health Policy Plan, 25, 454-466. https://doi. org/10.1093/heapol/czq065

Wong, L. P., \& Sam, I. C. (2010). Temporal changes in psychobehavioral responses during the $2009 \mathrm{H} 1 \mathrm{~N} 1$ influenza pandemic. Preventive Medicine, 51, 92-93. https://doi.org/10.1016/j.ypmed .2010.04.010

Xiang, Y. T., Yang, Y., Li, W., Zhang, L., Zhang, Q., Cheung, T., et al. (2020). Timely mental health care for the 2019 novel coronavirus outbreak is urgently needed. The Lancet Psychiatry, 7, 228-229. https://doi.org/10.1016/S2215-0366(20)30046-8

Publisher's Note Springer Nature remains neutral with regard to jurisdictional claims in published maps and institutional affiliations. 